Article

\title{
Frank and Fearless: Supporting Academic Career Progression for Women in an Australian Program
}

\author{
Polly Parker ${ }^{1, *}$, Belinda Hewitt ${ }^{2}$, Jennifer Witheriff ${ }^{1}$ and Amy Cooper ${ }^{1}$ \\ 1 Business School, University of Queensland, St. Lucia, QLD 4067, Australia; j.witheriff@uq.edu.au (J.W.); \\ a.cooper@uq.edu.au (A.C.) \\ 2 School of Social and Political Sciences, University of Melbourne, VIC 3010, Australia; \\ belinda.hewitt@melbourne.edu.au \\ * Correspondence: p.parker@uq.edu.au
}

Received: 20 December 2017; Accepted: 22 February 2018; Published: 27 February 2018

\begin{abstract}
The underrepresentation of women in senior positions continues to be a major challenge in higher education and most other industries. In Australia, the career trajectory for academic women stalls at a lower level than that of their male counterparts. Concern about this situation in one Australian university led to the design and delivery of a career progression program to support women's advancement from senior lecturer to associate professor. This study details the main features of the program, designed to facilitate women's transition from being leading academics to academic leaders through a focus on leadership and career progression. We report the participants' perceptions of its value based on survey data. We conclude that leadership development is difficult work and requires a supportive environment where risk-taking is encouraged, where frank and fearless feedback is provided, and where the individual is required to examine assumptions and biases and to assume a leadership identity.
\end{abstract}

Keywords: academic careers; gender; higher education; career progression; leadership

\section{Introduction}

The underrepresentation of women in senior positions in universities is a systemic worldwide phenomenon (Blackmore 2014; European Commission 2012) that mirrors women's low level of representation internationally and across industries (Catalyst 2012; Elliott and Stead 2008; Equality and Human Rights Commission 2011; McKinsey \& Co. 2012). The increase in female participation in higher education has not changed women's academic representation at senior levels in universities in Australia, which is similar to that in other Western countries (Aiston 2014; Gardiner et al. 2007; Morley 2013).

Barriers to women's career progression include sexism, stereotypes, unconscious bias, and work-family responsibilities (Eagly and Carli 2003; Morley 2013; O’Neil et al. 2008; Reitman and Schneer 2008; van den Brink and Benschop 2012). Women are often perceived as lacking ambition (Fels 2004; Litzky and Greenhaus 2007) or being deficient in ways that prevent them from achieving similar career outcomes to men (Shapiro et al. 2008). However, there is widespread agreement that women's commitment or abilities are not the problem (Carli and Eagly 2011; Morley 2013; O'Neil et al. 2008; Reitman and Schneer 2008). Instead, women's progression is structurally constrained by inequalities arising from factors such as culture, power dynamics, and the framing of merit (Lipton 2017). The reproduction of gender inequalities related to changes occurring within the higher education system internationally has been well researched and reported (Blackmore and Sachs 2007; Burkinshaw and White 2017; Eveline 2005; Morley 2014; White 2003).

In the neoliberal university climate, leadership has become the primary vehicle by which organizational development and transformation is to be achieved (Blackmore 2008; Morley 2013). A prevalent underpinning of neoliberalism is improving educational leadership effectiveness 
through a focus on "leadership standards, competency and capability frameworks" (Niesche 2013, p. 220). Thus, developing career and leadership has become synergistic with advancement in higher education, highlighting the resonance between two intertwined processes (Parker and Carroll 2009). The interrelatedness is evident in recent research and practice, which reflect a shared fundamental emphasis on learning from experience (Parker et al. 2012; Valcour et al. 2007), meaning-making for the career actors (Hall 2002; Khapova et al. 2007), holism (Parker and Carroll 2009), and leadership development (Goleman 2000; Heifetz 1994; Kram 1985; Shamir 1999). The interactive flow between leadership and career emerged from academic women's stories in an empirical study (Moore 2012). The qualities and norms of leadership expected in today's universities emphasize productivity, competitiveness, hierarchy, strategy, performativity, and an intense all-consuming commitment to paid work (Devine et al. 2011; Fitzgerald 2011). Leaders are expected to demonstrate authority, affective agency, and effective communication to achieve organizational goals and influence change (Morley 2013). This definition of leadership, however, is socially constructed, articulated, and reinforced by a social and policy agenda that is primarily shaped by men. Consequently, these qualities and expectations do not necessarily align well with women's academic careers and leadership. Despite an outward tolerance and even an expressed desire for diversity, a normative fantasy pertaining to success and leadership in higher education remains inherently male, which positions women consistently as "other" (Morley 2014).

The pipeline of women's progression into senior positions within the higher education sector is leaky, due in large part to a culture that rewards male practices and patterns of interaction that is not conducive to recognizing women's different styles and pathways. The numbers of women decrease at every stage of appointment on the academic scale (Carter and Silva 2010; Eveline 2005; van den Brink and Benschop 2012). In response, several universities have developed leadership programs to foster women's career progression to leadership roles (Dutta et al. 2011; Gardiner et al. 2007; Seritan et al. 2007; Thanacoody et al. 2006). These programs have been criticized for reinforcing inequities rather than reducing them, in that they individualize the problem and aim to modify women to better assimilate them into the dominant masculine culture (Colley 2001). Furthermore, trying to effect cultural change incurs an additional emotional burden for women as they strive to advance their academic careers with nontraditional trajectories (Burkinshaw and White 2017). In the politicized context of the neoliberal university, programs promoting women's leadership suit institutional agendas because they seemingly improve gender equity without challenging the fundamental structure and culture of an organization (Devos 2008). Nevertheless, in line with Morley (2013), we argue that such programs, if well designed, can and do add value beyond counting more women in senior ranks. Programs have the potential to be subversive, to challenge the status quo from within, pushing for change, particularly when the program is a genuine initiative by others to reach equitable outcomes for academic faculty and pursue a genuinely diverse leadership profile (White 2003). This paper contributes to the literature on leadership and women-only career progression programs by investigating the perceived benefits reported by a group of women who participated in a leadership program at a large university in Australia.

\subsection{Careers in Higher Education}

Internationally, women in academia are clustered at lower levels (Airini et al. 2011; Eveline 2005). The dearth of women in senior roles suggests that at some point careers peak, stall, or derail. A recent national study of Australian universities by Strachan et al. (2016) shows that the numbers of men and women are similar until they reach the top of the senior lecturer scale. In the 2011 academic workforce, $22 \%$ of women and $23.5 \%$ of men were employed at Level C (senior lecturer). The gender gap widens substantially after Level C, with more men attaining Level D (associate professor) positions than women, and the greatest gender difference is evident at the next step, with only $7 \%$ of women in academia holding Level E (full professor) positions compared to 19\% of men (Strachan et al. 2016). Other cross-national studies have noted a similar disparity between numbers of midcareer academics and those in the senior ranks, indicating that this is a global trend (Morley 2014). 
Promotion beyond senior lecturer into the professoriate specifically requires demonstrated leadership ability. Thus, at this point "career" and "leadership" become interrelated as markers of career progression, as expressed in promotion criteria. However, leadership is a broad concept that is often context-specific, such as in higher education, as noted above. Promotion processes are inherently political and "steeped in the discourse of neoliberalism, competition and metrics" (Sutherland-Smith 2014, p. 31). Despite the gender gap, there are marked similarities between men and women in terms of how they think about their university careers (Doherty and Manfredi 2010). The gap is therefore attributable to a range of factors, including personal (work-family interface and self-belief that affects motivation to achieve goals), professional (such as navigating masculine cultures and developing political savvy), and organizational shifts toward managerialism (Airini et al. 2011).

Women enact their careers differently from men (Powell and Mainiero 1992; Sullivan and Mainiero 2007), embedding paid work within a larger life context ( $\mathrm{O}^{\prime} \mathrm{N}$ Neil et al. 2008; Reitman and Schneer 2008). Numerous factors work in tandem. A nonlinear push-pull dynamic between family and work interrupts traditional patterns for women's careers (Cabrera 2007). The patterns are important, as they reflect times and spaces within women's careers when accumulation of human and social capital, critical for career success, is compromised (Probert 2005). Once women lose career momentum, they find it difficult to catch up, and the penalty persists throughout their careers (Reitman and Schneer 2008).

There are also differences in the ways women and men carry out leadership roles (Eagly and Johannesen-Schmidt 2007). A comprehensive meta-analysis of influential Multifactor Leadership Questionnaires (Avolio and Bass 1990) showed that women scored higher on transformational leadership measures (Eagly and Carli 2003). Transformational leaders develop and inspire their followers and consequently contribute to greater organizational success. While this measure should make women ideal candidates for leadership, other research has reported detrimental outcomes from differences that can impinge on success. Women practice a "softer" leadership style than men, which is less helpful in university settings, where the preferred style is "harder-nosed" (Doherty and Manfredi 2010). The result echoed Eagly and Johannesen-Schmidt's (2007) earlier finding that women display more democratic and participative leadership and less autocratic or directive leadership than men. Not only are these different, but also less likely to be valued or recognized. However, a double bind occurs at times when these "norms" are expected and not evident (Ely et al. 2011).

Gender stereotypes are well-documented factors that create resistance to women's influence and authority (Carli and Eagly 2011; Lipton 2017). Women's contributions are measured against male norms, particularly in research outputs in academia, which creates barriers for those with different styles and career patterns (Obers 2015). In the 1990s, gender inequality was described as tenacious because it was built into the structure of work organizations (Acker 1990). Three decades later, the situation is little different and a hidden curriculum creates cultural norms that hinder women's aspirations and careers (Morley 2014). It is one thing to understand what women do differently from men and how this may impact their career progression. Career and leadership factors interact and affect women's careers and their progression into academic leadership roles. Thus it is necessary to identify effective ways to develop women for career growth and leadership.

As indicated earlier, one response from universities has been to deliver women-only leadership development programs. University settings are strongly grounded in an ideology of meritocracy, so specific women's programs are not unanimously supported (van den Brink and Benschop 2012). They have also been criticized for encouraging women to enact their careers in ways that are more like men's, rather than valuing their unique contributions and qualities (Lipton 2017). Other key criticisms include that the programs are focused on fixing women rather than the systemic issues within the university context (Burkinshaw and White 2017; Strachan et al. 2016). Nevertheless, segregated programs, designed to provide a safe environment (Debebe 2011; Vinnicombe and Singh 2003), enable women to share their experiences authentically and help dispel the notion that they are deficient. 
Research suggests that these programs, classified as soft positive action, can engage women and be of real value (Doherty and Manfredi 2010).

\subsection{Career Progression for Women: Promoting Equity}

This study examines a program at a large Australian university that recognizes particular challenges in relation to achieving gender equity at senior levels. Analysis of the 2009 workforce data at the university found that gender parity at the level of lecturer and senior lecturer did not translate to gender parity at more senior levels. Women represented only $19.1 \%$ of academic staff at associate professor and professor levels, compared with $48.8 \%$ of nonacademic professional staff at the highest levels.

A comprehensive university-wide externally conducted review identified the systemic and structural barriers that may influence the promotion of women to senior academic positions. Attention was paid to aspects of such positions that would make them undesirable for women or seemingly unattainable (Morley 2014). A seminal Australian study (Blackmore and Sachs 2007, p. 13) identified dual problems of perception and structure that "work together in unpromising ways for women." Others have noted that a minority representation increases the challenge of being authentic in personal style and decision-making (Morley 2013). The university review and consultation with female academics led to a range of recommendations to address the barriers, including developing a women-only career development program, facilitated by women and focused on leadership and career progression, designed to facilitate women's transition from being leading academics to academic leaders. Other critical issues identified were a general lack of understanding and negative perceptions among the female participants about the academic promotion process, a perceived lack of female role models and mentors, and associated difficulties with balancing multiple roles within the workplace and competing demands. The university has now been running the career progression program for women who are or were at Level C since 2010. The explicit aim of the program is to support women's advancement from senior lecturer to associate professor. At this career transition point, a key requirement of the university's promotion criteria is that applicants demonstrate their leadership in the domains of teaching, research, engagement, and/or clinical service. Therefore, leadership recognition and development was a core element in the program design. Furthermore, leadership was positioned as a process and differentiated from a title or level of authority. We are mindful of research that highlights the dearth of women leaders in higher education as an outcome of a corporatized academy presenting a cruel paradox (Blackmore 2014; Lipton 2017). Therefore, rather than adopting a pejorative model, the program in question encourages a broad range of evidence to support strength-based leadership. The program focuses on enabling women to provide evidence of their leadership in a broad, flexible narrative grounded in their experience and addressing promotional criteria. The pedagogy focused on accentuating strengths to enhance personal leadership rather than any underlying assumption that the women were not leaders and needed to be shaped to fit an institutional model. In sum, the program was not about changing the women to be promotable, but focused on highlighting their capabilities and developing a narrative to align with and broaden the university criteria.

The content and structure of the program were tailored to address individual development needs while capitalizing on the power of the group structure and dynamics. Since its inception, the program was developed and has been facilitated by a female academic, and from 2012, the course has been facilitated in partnership with a specialized organizational leadership trainer (also female). The number of women in the program is limited to 24 , and each year it has been oversubscribed. Participants are required to write an application and, due to the large time commitment, obtain support from their head of school. Selection into the program is made on the basis of this application and commitment to attend all modules. Participants complete three modules over a 12-month period, comprising a 3-day core module followed by two 2-day modules spaced a few months apart to allow new learnings to be absorbed and practiced. Each module is grounded in learning activities based on personal experience and related to the published criteria for academic promotion, particularly those 
of demonstrated leadership. Sessions within modules include guided reflection through journaling (Daudelin 1996), experiential skill development, personal career planning, and academic portfolio development. Feedback is a feature of the program, with each participant undertaking a 360-degree leadership feedback assessment, as well as individual academic appraisal and review. Panels of senior university academic staff, both men and women, share their insights regarding academic career advancement and leadership though interactive group discussions. The support from female senior faculty also extends to group and individual mentoring of participants. These components are generally recognized as elements of effective career and leadership programs (Amagoh 2009; Clawson 2011; Ely et al. 2011).

In addition, the participants develop personal network maps, highlighting their diversity and breadth of support, access to information, and transmission of reputation, to emphasize the importance of developing appropriate relational and network support. The activity is reinforced with an introduction to the concept of developmental networks (Higgins and Kram 2001), peer coaching (Parker et al. 2008), and mentoring (Kram 1985; Ragins and Kram 2007). Peer coaching within and between modules enables participants to apply the coaching skills they learn to embed learning into day-to-day activities, maintain momentum, and provide ongoing support for each other (Parker et al. 2014).

Small groups of participants are assigned to senior female mentors in the organization and are expected to meet on a mutually agreed schedule for the length of the program. Generally, women receive less mentoring and grooming than men for senior management positions from top-level administrators such as vice chancellors, and instead receive support from less senior persons and from their families (Obers 2015; White et al. 2010). The value of both career and psychosocial support from mentors is long recognized to support vocational advancement and self-esteem (Kram 1985; Murphy and Kram 2014). A dearth of female role models and mentors may particularly affect the self-esteem building of female academics (Obers 2015). Implementing a mentoring program that pairs women with senior women may facilitate a positive culture with the potential to effect change and promote women and minority academics (Gibson 2006).

It should be noted that the Career Progression for Women program is one of several initiatives the university has implemented over time to create and promote a diversity agenda and, as part of that, gender equity. Initiatives such as participation in the UK's Athena Swan Awards to advance gender equality (see https:/ /www.ecu.ac.uk/equality-charters/athena-swan/); changes in selection, recruitment, and promotion polices to be more inclusive; pay equity reviews for all academics; and unconscious bias training have been implemented as part of the overall strategy to promote equal opportunity and address the underrepresentation of women at senior academic levels. Together, these initiatives reflect an awareness of the need for fundamental cultural change in higher education to counter disadvantage and discrimination (Bagilhole and White 2011; White 2003).

\section{Results}

\subsection{Comparing Social and Demographic Characteristics of Course Participants with Nonparticipants}

In our first analysis, we compare the women in our sample who participated in the Career Progression for Women (CPW) course to those who have not attended the course on a range of social and demographic characteristics. We do this to better understand whether there are systematic differences between women who were both nominated and selected to participate in the course and those who did not participate. In Table 1 we report results of a series of cross-tabulations with chi-square tests to ascertain whether the women who attended the career progression course were systematically different from women at Level $C$ in the broader university population. 
Table 1. Women at Level C between 2010 and 2015: social and demographic characteristics of women who have not attended the career progression course and women who have attended the course.

\begin{tabular}{|c|c|c|c|c|c|c|}
\hline & \multicolumn{2}{|c|}{$\begin{array}{l}\text { Have Not Participated } \\
\text { in Course }\end{array}$} & \multicolumn{2}{|c|}{$\begin{array}{l}\text { Participated in } \\
\text { Course }\end{array}$} & \multicolumn{2}{|r|}{ Total } \\
\hline & $\mathbf{N}$ & Column \% & $\mathbf{N}$ & Column \% & $\mathbf{N}$ & Column \% \\
\hline \multicolumn{7}{|l|}{ Relationship Status } \\
\hline Single & 15 & 16 & 4 & 9 & 19 & 14 \\
\hline Cohabiting & 12 & 13 & 6 & 13 & 18 & 13 \\
\hline Married & 61 & 66 & 34 & 72 & 95 & 68 \\
\hline Refused & 4 & 4 & 3 & 6 & 7 & 5 \\
\hline Total & 92 & 100 & 47 & 100 & 139 & 100 \\
\hline \multicolumn{7}{|c|}{ Pearson chi2(3) $=1.8059 \operatorname{Pr}=0.614$} \\
\hline \multicolumn{7}{|l|}{ Number of Children } \\
\hline No children & 26 & 28 & 11 & 22 & 37 & 26 \\
\hline 1 child & 15 & 16 & 9 & 18 & 24 & 17 \\
\hline 2 children & 41 & 44 & 21 & 42 & 62 & 43 \\
\hline 3 or more children & 12 & 13 & 9 & 18 & 21 & 15 \\
\hline Total & 94 & 100 & 50 & 100 & 144 & 100 \\
\hline \multicolumn{7}{|c|}{ Pearson chi2(3) $=1.1215 \operatorname{Pr}=0.772$} \\
\hline \multicolumn{7}{|l|}{ Born in Australia } \\
\hline Yes & 55 & 57 & 29 & 58 & 84 & 58 \\
\hline No & 41 & 43 & 21 & 42 & 62 & 42 \\
\hline Total & 96 & 100 & 50 & 100 & 146 & 100 \\
\hline \multicolumn{7}{|c|}{ Pearson chi2 $(1)=0.0068 \mathrm{Pr}=0.935$} \\
\hline \multicolumn{7}{|l|}{ Providing Care } \\
\hline Yes & 16 & 19 & 3 & 7 & 19 & 15 \\
\hline No & 69 & 81 & 39 & 93 & 108 & 85 \\
\hline Total & 85 & 100 & 42 & 100 & 127 & 100 \\
\hline \multicolumn{7}{|c|}{ Pearson chi2 $(1)=3.0146 \operatorname{Pr}=0.083$} \\
\hline \multicolumn{7}{|l|}{$\begin{array}{l}\text { Employment Interruption: } \\
\text { Career Break }\end{array}$} \\
\hline Yes & 55 & 61 & 27 & 56 & 82 & 59 \\
\hline No & 35 & 39 & 21 & 44 & 56 & 41 \\
\hline Total & 90 & 100 & 48 & 100 & 138 & 100 \\
\hline \multicolumn{7}{|c|}{ Pearson chi2 $(1)=0.3068 \operatorname{Pr}=0.580$} \\
\hline \multicolumn{7}{|l|}{$\begin{array}{l}\text { Employment Interruption: } \\
\text { Spouse Support }\end{array}$} \\
\hline Yes & 6 & 7 & 4 & 8 & 10 & 7 \\
\hline No & 84 & 93 & 44 & 92 & 128 & 93 \\
\hline Total & 90 & 100 & 48 & 100 & 138 & 100 \\
\hline \multicolumn{7}{|c|}{ Pearson chi2 $(1)=0.1294 \mathrm{Pr}=0.719$} \\
\hline \multicolumn{7}{|l|}{ Educational Qualification } \\
\hline $\mathrm{PhD}$ & 89 & 93 & 46 & 90 & 135 & 92 \\
\hline Professional Doctorate & 2 & 2 & 1 & 2 & 3 & 2 \\
\hline Master's & 1 & 1 & 3 & 6 & 4 & 3 \\
\hline Other postgrad & 4 & 4 & 1 & 2 & 5 & 3 \\
\hline Total & 96 & 100 & 51 & 100 & 147 & 100 \\
\hline \multicolumn{7}{|c|}{ Pearson chi2(3) $=3.3699 \operatorname{Pr}=0.338$} \\
\hline
\end{tabular}


We report the number $(\mathrm{N})$ and percent (\%) of women we observed in each group, with the chi-square tests reported below each factor. The results for relationship status, number of children, born in Australia, educational qualification, and whether they had career breaks for caring responsibilities or to support their spouse's career indicate that the CPW women were not significantly different on these factors from women who had not participated in CPW. The sample is ethnically diverse, with around $42 \%$ of women born overseas. Overall, the majority of women in our sample were in a relationship, and most of them were married. A large proportion of women did not have children (26\%), and most women with children had two children (43\%). It is worth noting here that a slightly higher proportion of women who attended the CPW had three or more children $(18 \%$ compared to $13 \%)$ and were also less likely to have no children at all compared to non-CPW women ( $22 \%$ compared to $28 \%$ ). This suggests the possibility that women with children are more likely to seek support. Seven percent of CPW women had caring responsibilities compared to $15 \%$ of non-CPW women, which is marginally significant at $p<0.08$. Relatedly, the main reason for taking an employment break was to provide care (69\% of women), whereas far fewer women took an employment break to support their spouse. The majority of women in our sample had a PhD, with only $8 \%$ of women having other types of qualifications.

\subsection{Women's Responses to Design Features of Program and Application of Program Learnings to Their Career}

We report the women's assessment of different components of the course and how beneficial they found them in Table 2. The most positively assessed aspect of the course was the guest speakers, rated by $89 \%$ of respondents as quite or extremely beneficial. The speakers included both men and women involved in an aspect of the promotion process, senior university leaders, or past participants who spoke about how they responded to the program. Also highly rated was the portfolio review, in which the women submitted their academic portfolio to be assessed independently for promotion to Level D by senior academics in the university, with $83 \%$ of women saying it was quite or extremely beneficial. Third highest was the female-only design of the program, which was seen to be quite or extremely beneficial by around $79 \%$ of participants. The networking opportunities; the 360-degree feedback, by which women received feedback about their performance and leadership from supervisors, peers, and staff; and the three-module design over 12 months were also perceived as among the most beneficial aspects of the course. Peer coaching and mentoring had more mixed responses, with most finding them quite beneficial, but not extremely beneficial. Journaling about the process, their experience with the course modules, and activities between modules were viewed as the least beneficial aspects of the course design.

Table 2. Evaluation of course features by women who attended the Career Progression for Women (CPW) course.

\begin{tabular}{ccc}
\hline Module Design & N & Column \% \\
\hline Not beneficial & 1 & 2 \\
Mildly beneficial & 2 & 4 \\
Unsure & 10 & 21 \\
Quite beneficial & 18 & 38 \\
Extremely beneficial & 16 & 34 \\
Total & 47 & 100 \\
\hline 360-Degree Feedback & $\mathbf{N}$ & Column \% \\
\hline Not beneficial & 2 & 4 \\
Mildly beneficial & 5 & 11 \\
Unsure & 4 & 9 \\
Quite beneficial & 19 & 40 \\
Extremely beneficial & 17 & 36 \\
Total & 47 & 100 \\
\hline
\end{tabular}


Table 2. Cont.

\begin{tabular}{|c|c|c|}
\hline Module Design & $\mathbf{N}$ & Column \% \\
\hline Academic Portfolio Review & $\mathbf{N}$ & Column \% \\
\hline Not beneficial & 1 & 2 \\
\hline Mildly beneficial & 4 & 9 \\
\hline Unsure & 3 & 7 \\
\hline Quite beneficial & 11 & 24 \\
\hline Extremely beneficial & 27 & 59 \\
\hline Total & 46 & 100 \\
\hline Peer Coaching & $\mathbf{N}$ & Column \% \\
\hline Not beneficial & 3 & 6 \\
\hline Mildly beneficial & 8 & 17 \\
\hline Unsure & 7 & 15 \\
\hline Quite beneficial & 21 & 45 \\
\hline Extremely beneficial & 8 & 17 \\
\hline Total & 47 & 100 \\
\hline $\begin{array}{l}\text { Mentoring from Senior } \\
\text { Women }\end{array}$ & $\mathbf{N}$ & Column \% \\
\hline Not beneficial & 4 & 9 \\
\hline Mildly beneficial & 6 & 13 \\
\hline Unsure & 11 & 23 \\
\hline Quite beneficial & 17 & 36 \\
\hline Extremely beneficial & 9 & 19 \\
\hline Total & 47 & 100 \\
\hline Guest Speakers & $\mathbf{N}$ & Column \% \\
\hline Not beneficial & 1 & 2 \\
\hline Mildly beneficial & 3 & 7 \\
\hline Unsure & 1 & 2 \\
\hline Quite beneficial & 23 & 50 \\
\hline Extremely beneficial & 18 & 39 \\
\hline Total & 46 & 100 \\
\hline Keeping a Journal & $\mathbf{N}$ & Column \% \\
\hline Not beneficial & 10 & 21 \\
\hline Mildly beneficial & 8 & 17 \\
\hline Unsure & 8 & 17 \\
\hline Quite beneficial & 16 & 34 \\
\hline Extremely beneficial & 5 & 11 \\
\hline Total & 47 & 100 \\
\hline Networking & $\mathbf{N}$ & Column \% \\
\hline Not beneficial & 0 & 0 \\
\hline Mildly beneficial & 5 & 11 \\
\hline Unsure & 6 & 13 \\
\hline Quite beneficial & 12 & 26 \\
\hline Extremely beneficial & 24 & 51 \\
\hline Total & 47 & 100 \\
\hline Women Only & $\mathbf{N}$ & Column \% \\
\hline Not beneficial & 3 & 6 \\
\hline Mildly beneficial & 2 & 4 \\
\hline Unsure & 5 & 11 \\
\hline Quite beneficial & 9 & 19 \\
\hline Extremely beneficial & 28 & 60 \\
\hline Total & 47 & 100 \\
\hline
\end{tabular}


Table 2. Cont

\begin{tabular}{ccc}
\hline Module Design & N & Column $\%$ \\
\hline Academic Portfolio Review & N & Column $\%$ \\
\hline Graduation Dinner & N & Column \% \\
\hline Not beneficial & 5 & 11 \\
Mildly beneficial & 6 & 14 \\
Unsure & 17 & 39 \\
Quite beneficial & 11 & 25 \\
Extremely beneficial & 5 & 11 \\
Total & 44 & 100 \\
\hline Off-site Training & $\mathbf{N}$ & Column $\%$ \\
\hline Not beneficial & 1 & 2 \\
Mildly beneficial & 5 & 11 \\
Unsure & 4 & 9 \\
Quite beneficial & 15 & 33 \\
Extremely beneficial & 21 & 46 \\
Total & 46 & 100 \\
\hline
\end{tabular}

Note: total numbers vary due to differences in missing values for each variable.

In Table 3 the results show women's reflections on whether they used the learnings from the program and their perceptions of whether the program contributed to their career since. First, the results show that most women felt that they had successfully applied some or all of the learnings obtained in the course to their academic career, with $56 \%$ indicating they had been very successful and $35 \%$ moderately successful at applying aspects of the course to their career. Second, an overwhelming majority $(96 \%)$ reported that the program had contributed positively to their career.

Table 3. Participants' assessment of broader contributions of CPW to their career.

\begin{tabular}{ccc}
\hline $\begin{array}{c}\text { Overall, How Successful Have You Been at } \\
\text { Applying This Learning to Your Career? }\end{array}$ & N & Column \% \\
\hline Very & 27 & 56 \\
Moderately & 17 & 35 \\
Not at all & 4 & 8 \\
Total & 48 & 100 \\
\hline $\begin{array}{c}\text { Please Indicate If You Think Undertaking CPW } \\
\text { Contributed Positively to Your Career }\end{array}$ & $\mathbf{N}$ & Column \% \\
\hline Yes & 45 & 94 \\
No & 3 & 6 \\
Total & 48 & 100 \\
\hline
\end{tabular}

\subsection{Open-Ended Comments: Qualitative Responses to the Program}

Respondents were asked if they had other comments or feedback about the program that they wished to share. The overall results of this open-ended question are presented in Figure 1. The findings indicate that $89.66 \%$ of the women had positive assessments of their experience of the course, $3.45 \%$ were ambivalent, and $6.90 \%$ had negative assessments. Two main themes emerged from the positive comments: personal growth and development, both professional and personal, and reflections on the value of the program for other women and in the context of the broader university environment. 


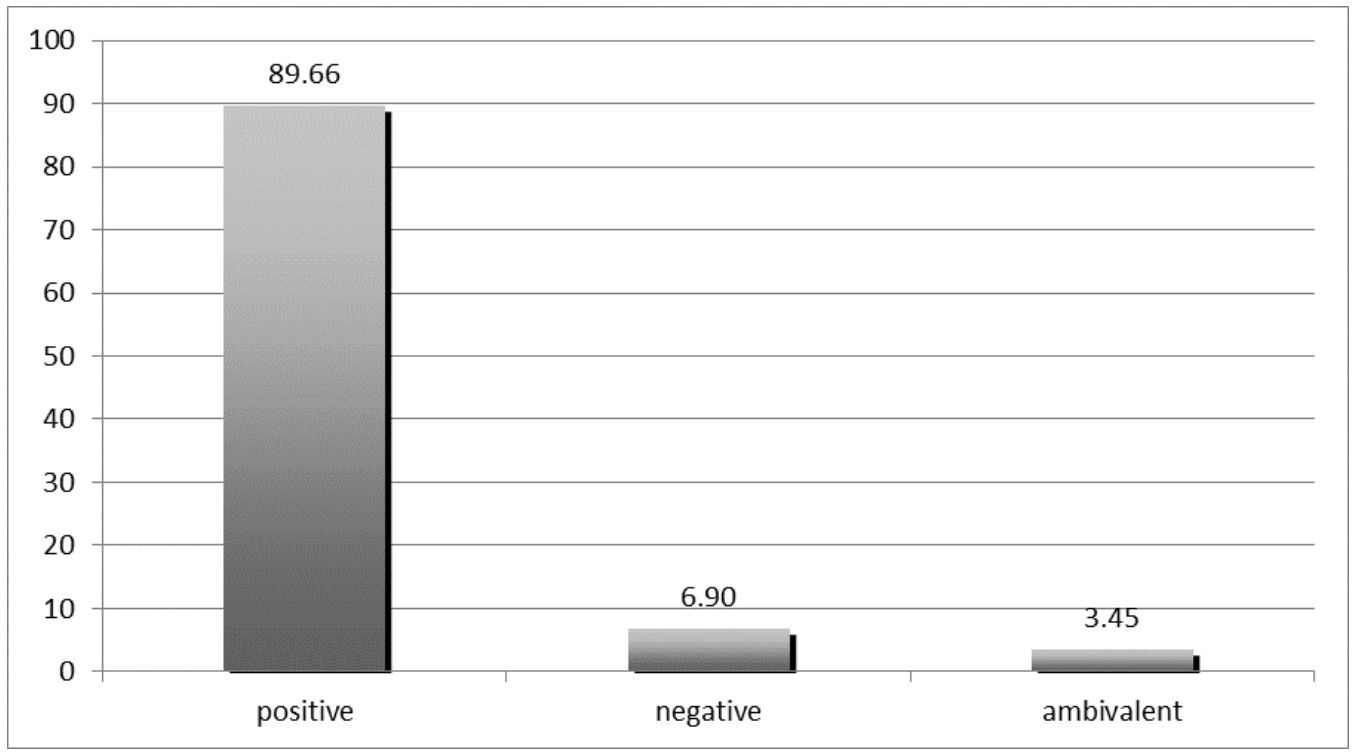

Figure 1. Summary of verbatim responses to open-ended survey question "Do you have any other comments or feedback about the CPW that you would like the opportunity to share?"

Within the first theme of personal development, approximately half of the women indicated that they had a better understanding of themselves in relation to their career and aspirations. For some, this meant reconsidering their possibilities for the future, exemplified by the following quote:

"CPW makes you think differently and really helps you in understanding who you are, your core values, what you believe in, and the change you want to bring about and your leadership skills, which will enable you to create the change you want as an academic." (\#1)

Thinking differently was also reflected in women's perceptions of the dramatic changes they felt in themselves and their attitude or approach to their career; for example:

"The CPW program was a game changer for me. I think it created a dramatic change in my attitude in many aspects of my work. Extremely positive." (\#4)

"It was a transformative program for me and I do not think I would have achieved my current position without it." (\#25)

Some of the women reported an acceptance and better understanding of their position within the university.

"The program gave me time to reflect on my career and my choices. I am now more accepting of my current position even though I have not yet applied for promotion." (\#13)

"It helped me to locate myself in the institution and work out what was important for me." (\#29)

As exemplified in this series of quotes, for many women who participated, the program was transformative in a range of ways. This is indicative of the potential to change and transform how women see themselves and the value of what they contribute to the university. The second main theme concerned women's reflections on the value of the course for other women and the university more broadly:

"I frequently recommend the program to other staff members." (\#8) 
“This was an excellent program, which I have recommended to several colleagues." (\#28)

Several of the women commented on the importance of the program and advocated for its continuation by the university:

"I think this program is incredibly valuable. I would like a 'refresher' half-day course each year or every other year, to help facilitate continued progression and development." (\#15)

"Really pleasing that [university] have continued to grow and develop this program. I know a lot of women who have done the course and benefitted in a whole range of ways." (\#17)

From these quotes, there is a sense that many individuals who participated in the course benefited from the program and that institutionally it signaled a commitment to improving gender equality. Nevertheless, while individuals benefited, there was no sense of an accompanying structural change. In this respect, a number of the women's responses were more ambivalent. While positive about the program, they were skeptical about any real change, particularly with regard to the university's capacity for genuine change in relation to gender.

"The culture at [university] can only change if senior women change that culture. Career progression is one thing, but collaborative, diverse, and equitable safe work places should be our ultimate aim." (\#12)

“The program was really good and I enjoyed getting to know so many great [university] women. However, the main impediments to women's advancement has little to do with them. I think there is a great lack of implicit bias and gender issue awareness among those in senior positions at [university] (Heads of Schools and up)." (\#18)

“To give context to the above, it is an excellent program. However, being placed in a service role with constantly changing expectations and increasing workload, I feel this has precluded possible career development." (\#30)

These comments, while generally positive about the women's individual experiences, strongly echo concerns raised in the feminist literature on the real capacity for change (Devos 2008; Morley 2013). In these quotes, the women articulate the structural and cultural barriers that are the reality that female academics face in their careers, irrespective of any individual change they experience. Removing these barriers requires higher-level institutional change, which underscores the importance of running women-only programs as one component of a broader range of strategies to achieve genuine institutional diversity. Not all participants were positive; those who viewed the course in a more negative light highlighted the time commitment required as a major burden, as exemplified by the following quotes:

"The time commitment for the program was very intense and similar commitments were not required by male staff members." (\#3)

"The course was way too time consuming. There was too much emphasis on finding our values. Most women already know their values." (\#24)

These quotes, particularly the reference that male staff members do not have to go through the same time-intensive program as women to progress in the university, highlight the additional burden on women who are interested in institutional progression. 


\section{Discussion}

The aim of this study was to provide an overview of the perceived benefits of a leadership program for women in a major Australian university. Prior feminist literature on the position of women in higher education has criticized this type of approach, because it does not directly undermine and challenge the misogynist structure of the neoliberal university, but rather forces women to contort themselves to fit within it (Burkinshaw and White 2017; Lipton 2017). However, our findings suggest that a well-designed course can empower and enable women to challenge the system while working within it, reinforcing a successful approach to change, as noted by Bilimoria et al. (2008). The only way to change entrenched institutional logic is to make experiences of discrimination visible (Sinclair 2000), and the career progression program is one such avenue.

The guest speakers were the most highly rated aspect of the program, with $87 \%$ of participants agreeing that they were quite or extremely beneficial. The speakers were both male and female academic leaders, who shared their insights on the promotion process and their personal experience of navigating an academic career. Their experiences challenged the assumption of a linear academic career; the concept of merit being only an objective requirement based on ability, skill, and achievement (Lipton 2017); and the notion that leadership is about position held in service or engagement roles. The guest speaker sessions were an integral aspect of the workshop design and acted as an impetus to connect presenters and participants following the presentations. Furthermore, the participants were encouraged by the facilitators to reflect on the content though peer coaching and journaling, both recognized ways of promoting relational learning (Parker et al. 2018).

A key aspect of the design was the multiple sources of developmental feedback, including portfolio review, 360-degree feedback, and peer coaching. Each of these provided developmental feedback that was necessary to identify strengths, areas for change in focus, and strategies for growth (Ely et al. 2011). Participants' feedback suggests that one of the barriers to applying for promotion is uncertainty about how one's performance compares to the university selection criteria and how it aligns with that of other academics outside of one's professional area. This is of particular concern for women whose academic career path may not be perceived as traditional or standard due to career breaks and other barriers. The program encourages and supports women to think differently and more holistically about their careers, positioning achievements relative to opportunity and valuing different approaches to leadership. By doing so, women could establish a career narrative rather than a list of publications and achievements in academic CVs recognized as neoliberal measures that epitomize traditional and linear career development markers (Lipton 2017; Niesche 2013). The survey results indicate that these features were highly valued by the participants.

Eighty-seven percent of the survey respondents identified the portfolio review process as beneficial or extremely beneficial. This feedback, while sometimes challenging to receive, facilitated a change in thinking about the how the participants "ticked the boxes" required for promotion. The feedback challenged the self-limiting assumptions that many participants had about their readiness for promotion and added to their developing a holistic view of their career. The portfolio review was a critical element in the program design, and each participant's portfolio was given to two senior academic reviewers, often heads of departments, for assessment. The reviewers were selected based on their experience in the university promotion process, including one from the participant's discipline and the other from a different discipline (which ensured that the language was readily understood without jargon). Reviewers provided written feedback, which could be anonymous. However, many reviewers not only declared themselves, but also invited the participants to meet for further coaching around improving their portfolios.

The women-only program design (in terms of both facilitation and participation) was essential to create an experience that established a safe space for learning and encouraged the women to build a community of peer support, and it was strongly supported by the participants of this program. While there is criticism that women's programs focus on "fixing women" and inherently blame them for their own inequitable outcomes (Pyke 2018) rather than focusing on the university culture (Burkinshaw 
and White 2017), support for women-only programs identifying the opportunity to learn and share with women validates their experiences (Debebe 2011). When women are in a majority position, in contrast to the more familiar male-dominated work context, this can provoke powerful insights (Ely et al. 2011). More women-only programs that support participants in navigating the challenges of the higher education context are required.

Another highly valued component of the course was the creation of developmental networks. The women-only program design was also essential to this experience, as it provided an avenue for sustaining relationships through an established community of peer support, building from a shared experience. Developmental networks are effective ongoing support systems (Murphy and Kram 2014). They are also critical elements of any effective leadership development program (Ely et al. 2011). The findings indicate that $77 \%$ of respondents considered networking to be quite or extremely beneficial, supporting evidence that networking is critical to the advancement of women's leadership as a means of mobilizing the work of change.

The open-ended qualitative findings from the survey suggest that women who participated in the Career Progression for Women program evaluated it highly on average, and many perceived that they obtained career benefits and advantages from participating. Most of the women found the course transformative, and this suggests that women-only programs have the potential for "tempered radicalism." The leadership development focus, incorporating technical aspects of preparing for promotion into a more strategic agenda of tailoring the program to support women's trajectory into senior academic positions, was mostly successful. However, even though the program clearly inspired and enabled women to view themselves and their positions within the university differently, the change was individual rather than structural. This dilemma was also a main theme of the open-ended responses and strongly reflects the feminist critiques of such programs being implemented as stand-alone solutions.

Objectively, the program was successful, in that $32 \%$ of participants have been promoted to Level D, and the proportion of women represented at Level D in the university has increased by $5 \%$ since the course has been running. The increase in numbers not only benefits individual women, but also contributes to significant changes in the demographic balance; women cannot be what they cannot see. More role models also gives women more options of leadership styles to emulate. Broader representation across all forms of leadership is essential to address the dearth of women at senior levels, and to improve statistics that reflect attainment levels. Dynamics subtly shift across environments in which these women work.

Nevertheless, gender equity will not be solved by merely "count[ing] more women into elite systems" (Morley 2014, p. 124). As Karen Pyke noted, a sense of safety and inclusivity means that all forms of discrimination and bias, including bullying and sexual harassment, require institution-wide structural change to align the rhetoric of diversity with the lived experience of all academics (Pyke 2018). The situation that initially promoted the program has also resulted in changes to key aspects of the university's strategic plan, which now includes a strong focus on attracting and supporting diversity among staff and students with identifiable targets. Thus, although the profile of the leadership program has increased because of the larger numbers of women being promoted, and gaining recognition collectively is creating a climate for more change, the program is not expected to effect change alone, and other initiatives are being implemented to address systemic inequities. One example is engaging more diverse promotion panels to increase understanding of the challenges women confront in achieving leadership roles. This is just one more part of the larger challenge that frames the issue of increasing the number of women in senior roles. Thus, highlighting the readiness for gender equity within the university is a major outcome of the program. It demonstrates an increasing willingness to engage with women to understand the barriers they confront in their careers and underpins the evolution of a larger cultural change taking place within the university setting. Future programs may consider including sexual harassment, as we have become more and more aware over the past couple of years of how pervasive the problem is. 


\section{Materials and Methods}

\subsection{Data and Analytic Sample}

The data come from a survey of academics at an Australian university. The survey was not commissioned by the university administration to specifically examine the program, but more broadly targeted to better understand men's and women's career progression from senior lecturer (Level C) to associate professor (Level D). The sample was drawn from administrative data obtained from the Human Resources division at the university comprising all academics who were at Level C between 2010 and 2015. The initial administrative data sample frame comprised 1038 academics. After excluding those who were ineligible and those who had left the university, the final sample frame comprised 1009 people. The survey was conducted online using Survey Monkey. A pilot survey was conducted with 17 people in June 2016, with follow-up face-to-face interviews with 6 of those respondents, and the survey was modified based on their feedback. The full survey went into the field in early October 2016. All potential participants were contacted via university email addresses and participation was voluntary. To maximize response rates, two follow-up reminders were sent four weeks and eight weeks after the initial invitation. In total, 385 people responded, with 346 fully completed surveys and 39 partially completed surveys received. An overall response rate of $38 \%$ was achieved, which is comparable with other surveys using similar samples and approaches.

The analytic sample for the present study comprised 147 women who responded to the survey and provided valid responses on the variables of interest. Of the women who responded to the survey, 48 participated in the program between 2010 and 2016. This was 55\% of the 88 women who participated in the program and were still employed by the university. The women who participated in the career progression course were asked a series of additional questions in the survey about their experience with the course and their opinions about whether or not the course was helpful for them. The responses of these women are the focus of this paper.

\subsection{Measures}

\section{Social and Demographic Characteristics}

All survey participants were asked to provide social and demographic information as well as information about their career. We use a selection of these measures in the current paper. Relationship status comprised three groups: single (not in a relationship), cohabiting (living with someone in a relationship, but not married), and legally married. Number of children was categorized into no children, one child, two children, or three or more children. We also differentiated between whether the respondent was born in Australia or overseas $(1=$ yes, $2=$ no). Participants were asked if they were currently providing child care or elder care $(1=$ yes, $2=\mathrm{no})$, and if they had taken significant career breaks to provide care or to support their spouse's career $(1=$ yes, $2=$ no). Respondents were also asked for their highest level of academic qualification: $\mathrm{PhD}$, professional doctorate, master's, or other postgraduate qualification.

\subsection{Questions Asked of Course Participants}

The survey respondents who indicated that they had participated in the Career Progression for Women program were asked additional questions about how beneficial they thought 11 features of the program were: the three-module design, 360-degree feedback, portfolio review, peer coaching, mentoring from senior women, guest speakers, keeping a journal, networking, women only, graduation dinner, and off-site training. Responses were on a 5 -point Likert scale: $1=$ not beneficial, $2=$ mildly beneficial, 3 = unsure, 4 = quite beneficial, and $5=$ extremely beneficial.

In addition, this group of women were asked two questions about the course's contributions to their career. The first was "Overall, how successful have you been at applying this learning to your career?" Possible responses were 1 = very, 2 = moderately, and 3 = not at all. The second was "Please 
indicate if you think undertaking CPW contributed positively to your career" ( $1=$ yes, $2=$ no). Course participants were also asked to respond to an open-ended question: "Do you have any other comments or feedback about the CPW that you would like the opportunity to share?"

\subsection{Analytic Procedure}

Analysis proceeded in four main stages. First, to examine whether the 48 women who participated in the Career Progression for Women course were different from other women at Level C, we compared the social and demographic characteristics of women who had and had not participated in the course. Group differences were assessed using chi-square tests that compared the distribution of the observed frequencies to the expected frequencies that would be present if the distributions were identical for the women who had participated and those who had not. If these differed enough, the chi-square test was significant $(p<0.05)$. Second, we undertook a descriptive analysis of women's responses to a series of questions about the design features of the Career Progression for Women course. Third, we undertook a descriptive analysis of the two questions regarding the contribution of the course to the women's careers. Fourth, we undertook a qualitative analysis of the open-ended responses to comments about the career progression course. Of the 48 participants in the course who responded to the survey, 33 provided answers to the open-ended question and 29 of the responses were relevant to the current paper. The answers to this open-ended question did not lend themselves to a full qualitative analysis, as they were mostly short sentences. Nevertheless, the information provided was sufficient to identify several themes.

\section{Conclusions}

For women, transitioning from being a leading academic to an academic leader requires more than a promotion to a higher organizational level. It requires changes in mindset and identity. It is difficult work and requires systemic change and personal courage in a supportive environment. The CPW program creates a learning environment where risk-taking is encouraged, where frank and fearless feedback is provided, and where academics are required to examine assumptions and biases and assume a leadership identity. Thus there are benefits in challenging the rhetoric and traditional patterns of career pathways in higher education as a means of encouraging cultural change. Until we reach a critical mass of women, we will continue to focus on both external context and internal courage.

Acknowledgments: We wish to thank the program participants. We would also like to thank the three anonymous reviewers for their constructive feedback on the paper.

Author Contributions: Polly Parker led the project including the overall conceptual design of the evaluation. She contributed to framing and writing the paper and coordinating the efforts of other authors. Belinda Hewitt contributed to the conceptual and overall development of the project and survey. She processed the data and conducted all the analysis for the current paper, including writing the methods and results sections and has edited and provided feedback on other sections of the manuscript. Jennifer Witheriff contributed to the conceptual and overall development of the project and survey. She has deep knowledge of the program and links with extant literature. Amy Cooper contributed to the overall development of the project, performed literature reviews, administered the pilot survey, subsequent interviews and built and administered the full survey.

Conflicts of Interest: The authors declare no conflict of interest. The founding sponsors had no role in the design of the study; in the collection, analyses, or interpretation of data; in the writing of the manuscript, and in the decision to publish the results.

\section{References}

Acker, Joan. 1990. Hierarchies, jobs, bodies: A theory of gendered organizations. Gender and Society 4: 139-58. [CrossRef]

Airini, Sunny Collings, Lindsey Conner, Kathryn McPherson, Brenda Midson, and Cheryl Wilson. 2011. Learning to be leaders in Higher Education: What helps or hinders women's advancement as leaders in universities. Educational Management Administration and Leadership 39: 44-62. [CrossRef] 
Aiston, Sarah Jane. 2014. Leading the academy or being led? Hong Kong women academics. Higher Education Research E Development 33: 59-72.

Amagoh, Francis. 2009. Leadership development and leadership effectiveness. Management Decision 47: 989-99. [CrossRef]

Avolio, Bruce J., and Bernard M. Bass. 1990. Transformational Leadership Development: Manual for the Multifactor Leadership Questionnaire. Palo Alto: CA Press.

Bagilhole, Barbara, and Kate White, eds. 2011. Gender, Power and Management: A Cross-Cultural Analysis of Higher Education. New York: Palgrave Macmillan.

Bilimoria, Diana, Simy Joy, and Xiangfen Liang. 2008. Breaking barriers and creating inclusiveness: Lessons from organizational transformation to advance women faculty in academic science and engineering. Human Resource Management 47: 423-41. [CrossRef]

Blackmore, Jill. 2008. Re/positioning women in educational leadership: The changing social relations and politics of gender in Australia. In Women Leading Education across the Continents: Sharing the Spirit, Fanning the Flame. Edited by Jill Blackmore. Lanham: Rowman and Littlefield Education, pp. 73-83.

Blackmore, Jill. 2014. Wasting talent? Gender and hte problematics of academic disenchantment and disengagement with leadership. Higher Education Research \& Development 33: 86-99.

Blackmore, Jill, and Judyth Sachs. 2007. Performing and Reforming Leaders: Gender, Educational Restructuring, and Organizational Change. Albany: State University of New York Press.

Burkinshaw, Paula, and Kate White. 2017. Fixing the women or fixing universities: Women in HE leadership. Administrative Sciences 7. [CrossRef]

Cabrera, Elizabeth F. 2007. Opting out and opting in: Understanding the complexities of women's career transitions. Career Development International 12: 218-37. [CrossRef]

Carli, Linda L., and Alice H. Eagly. 2011. Gender and leadership. In The Sage Handbook of Leadership. Edited by Bryman Alan, D. Collinson, K. Grint, B. Jackson and M. Uhl-Bien. London: Sage, pp. 103-17.

Carter, Nancy M., and Christine Silva. 2010. Women in management: Delusions of progress. Harvard Business Review 88: 19-22.

Catalyst, Census. 2012. Catalyst Census: Fortune 500 Women Board Directors. New York: Catalyst Census.

Clawson, James G. S. 2011. The Handbook for Teaching Leadership: Knowing, Doing \& Being. Academy of Management Learning $\mathcal{E}$ Education 10: 535.

Colley, Helen. 2001. Righting rewritings of the myth of Mentor: A critical perspective on career guidance mentoring. British Journal of Guidance and Counselling 29: 177-97. [CrossRef]

Daudelin, Marilyn Wood. 1996. Learning from experience through reflection. Organizational Dynamics 24: 36-49. [CrossRef]

Debebe, Gelaye. 2011. Creating a Safe Environment for Women's Leadership Transformation. Journal of Management Education 35: 679-712. [CrossRef]

Devine, Dympna, Bernie Grummell, and Kathleen Lynch. 2011. Crafting the elastic self? Gender and identities in senior appointments in Irish education. Gender, Work and Organization 18: 631-49. [CrossRef]

Devos, Anita. 2008. Where enterprise and equity meet: The rise of mentoring for women in Australian Universities. Discourse: Studies in the Cultural Politics of Education 29: 195-205. [CrossRef]

Doherty, Liz, and Simonetta Manfredi. 2010. Improving women's representation in senior positions in universities. Employee Relations 32: 138-55. [CrossRef]

Dutta, Rina, Sarah L. Hawkes, Elizabeth Kuipers, David Guest, Nicola T. Fear, and Amy C. Iversen. 2011. One year outcomes of a mentoring scheme for female academics: A pilot study at the Institute of Psychiatry, King's College London. BMC Medical Education 11: 13-22. [CrossRef] [PubMed]

Eagly, Alice H., and Linda L. Carli. 2003. The female leadership advantage: An evaluation of the evidence. Leadership Quarterly 14: 807-34. [CrossRef]

Eagly, Alice H., and Mary C. Johannesen-Schmidt. 2007. Leadership style matters: The small, but important, style differences between male and female leaders. In Handbook on Women in Business and Management. Edited by D. Bilimoria and S. K. Piderit. Cheltenham: Edward Elgar.

Elliott, Carole, and Valerie Stead. 2008. Learning from leading women's experience: Towards a sociological understanding. Leadership 4: 159-80. [CrossRef] 
Ely, Robin J., Herminia Ibarra, and Deborah M. Kolb. 2011. Taking Gender into Account: Theory and Design for Women's Leadership Development Programs. Academy of Management Learning E Education 10: 474-93. [CrossRef]

Equality and Human Rights Commission. 2011. Sex and Power-Who Runs Britain? London: Equality and Human Rights Commission.

European Commission. 2012. Structural Change in Research Institutions: Enhancing Excellence, Gender Equality and Efficiency in Research and Innovation. Brussels: European Commission.

Eveline, Joan. 2005. Women in the ivory tower. Journal of Organizational Change Management 18: 641-58. [CrossRef] Fels, Anna. 2004. Do women lack ambition? Harvard Business Review 82: 50-60. [PubMed]

Fitzgerald, Tanya. 2011. Troubling leadership? Gender, leadership and higher education. Paper presented at the Australian Association for Research in Education Conference, Hobart, Australia, 27 November-1 December.

Gardiner, Maria, Marika Tiggemann, Hugh Kearns, and Kelly Marshall. 2007. Show me the money! An empirical analysis of mentoring outcomes for women in academia. Higher Education Research and Development 26: 425-42. [CrossRef]

Gibson, Sharon K. 2006. Mentoring of women faculty: The role of organizational politics and culture. Innovative Higher Education 31: 63-79. [CrossRef]

Goleman, Daniel. 2000. Leadership that gets results. Harvard Business Review 78: 78-90.

Hall, Douglas T. 2002. Careers in and out of Organizations. Thousand Oaks: Sage.

Heifetz, Ronald A. 1994. Leadership without Easy Answers. Cambridge: Harvard University Press.

Higgins, Monica C., and Kathy E. Kram. 2001. Reconceptualizing mentoring at work: A developmental network perspective. Academy of Management Review 26: 264-88.

Khapova, Svetlana, Michael B. Arthur, and Celeste P. M. Wilderom. 2007. The subjective career in the knowledge economy. In Handbook of Career Studies. Edited by P. Gunz Hugh and Maury Peiperl. New York: Sage, pp. 114-30.

Kram, Kathy E. 1985. Mentoring at Work: Developmental Relationships in Organizational Life. Glenview: Scott Foresman. Lipton, Briony. 2017. Measures of success: Cruel optimism and the paradox of academic women's participation in Australian higher education. Higher Education Research E Development 36: 486-97.

Litzky, Barrie, and Jeffrey Greenhaus. 2007. The relationship between gender and aspirations to senior management. Career Development International 12: 637-59. [CrossRef]

McKinsey \& Co. 2012. Making the Breakthrough. Paris: McKinsey \& Co.

Moore, Anne. 2012. Looking for Flow in the Storylines of Leadership and Career in Women's Development. Master' thesis, University of Auckland, Auckland, New Zealand.

Morley, Louise. 2013. The rules of the game: Women and the leaderist turn in higher education. Gender and Education 25: 116-31. [CrossRef]

Morley, Louise. 2014. Lost leaders: Women in the global academy. Higher Education Research E Development 33: 114-28.

Murphy, Wendy, and Kathy Kram. 2014. Strategic Relationships at Work. New York: McGraw Hill.

Niesche, Richard. 2013. Politicizing articulation: Applying Lyotard's work to the use of standards in educational leadership. International Journal of Leadership in Education 16: 220-33. [CrossRef]

O'Neil, Deborah A., Margaret M. Hopkins, and Diana Bilimoria. 2008. Women's careers at the start of the 21st century: Patterns and Paradoxes. Journal of Business Ethics 80: 727-43. [CrossRef]

Obers, Noëlle. 2015. Influential structures: Understanding the role of the head of department in relation to women academics' research careers. Higher Education Research \& Development 34: 1220-32.

Parker, Polly, and Brigid Carroll. 2009. Leadership development from a careers perspective. Leadership 5: 261-83. [CrossRef]

Parker, Polly, Douglas T. Hall, and Kathy E. Kram. 2008. Peer Coaching: A relational process for accelerating career learning. Academy of Management Learning and Education 7: 487-503. [CrossRef]

Parker, Polly, Kathy E. Kram, and Douglas T. Hall. 2012. Exploring Risk Factors in Peer Coaching: A Multilevel Approach. Journal of Applied Behavioral Science 49: 361-87. [CrossRef]

Parker, Polly, Kathy E. Kram, and Douglas T. Hall. 2014. Peer coaching: An untapped resource for development. Organizational Dynamics 43: 122-29. [CrossRef]

Parker, Polly, Douglas T. Hall, Kathy E. Kram, and I. Wasserman. 2018. Peer Coaching at Work: Principles and Practices. San Francisco: Stanford University Press. 
Powell, Gary N., and Lisa A. Mainiero. 1992. Cross-currents in the river of time: Conceptualizing the complexities of women's careers. Journal of Management 18: 215-37. [CrossRef]

Probert, Belinda. 2005. I just couldn't fit in: Gender and unequal outcomes in academic careers. Gender, Work and Organization 12: 50-72. [CrossRef]

Pyke, Karen D. 2018. Insitutional betrayal: Inequity, discrimination, bullying, and retaliation in academia. Sociological Perspectives 61: 5-13. [CrossRef]

Ragins, B. R., and Kathy E. Kram. 2007. The Handbook of Mentoring at Work: Research, Theory and Practice. Los Angeles: Sage Publications.

Reitman, Frieda, and Joy A. Schneer. 2008. Enabling the new careers of the 21st century. Organization Management Journal 5: 17-28. [CrossRef]

Seritan, Andreea L., Robinder Bhangoo, Sylvia Garma, Jane DuBé, Ju Hui Park, and Robert Hales. 2007. Society for women in academic psychiatry: A peer mentoring approach. Academic Psychiatry 31: 363-66. [CrossRef] [PubMed]

Shamir, Boas. 1999. Leadership in boundaryless organizations: Disposable or indispensable? European Journal of Work and Organizational Psychology 8: 49-71. [CrossRef]

Shapiro, Mary, Cynthia Ingols, and Stacy Blake-Beard. 2008. Confronting career double binds: Implications for women, organizations and career practitioners. Journal of Career Development 34: 309-33. [CrossRef]

Sinclair, Amanda. 2000. Teaching managers about masculinities: Are you kidding? Management Learning 31: 83-101. [CrossRef]

Strachan, Glenda, D. Peetz, G. Whitehouse, J. Bailey, K. Broadbent, C. Troup, and M. Nesic. 2016. Women, Careers and Universities. Where to from Here? Nathan: Centre for Work, Organisation and Wellbeing (WOW).

Sullivan, Sherry E., and Lisa Mainiero. 2007. Women's kaleidoscope careers A new framework for examining women's stress across the lifespan. Research in Cccupational Stress and Wellbeing 6: 205-38.

Sutherland-Smith, Wendy. 2014. You're on the cusp but not there yet. Braving the promotion process. In Career Moves: Mentoring for Women Advancing Their Career and Leadership in Academia. Edited by Athena Vongalis-Macrow. Rotterdam: Sense Publishers, pp. 17-34.

Thanacoody, P. Rani, Timothy Bartram, Michelle Barker, and Kerry Jacobs. 2006. Career progression among female academics: A comparative study of Australia and Mauritius. Women in Management Review 21: 536-53. [CrossRef]

Valcour, Monique, Lotte Bailyn, and Maria Alejandra Quijada. 2007. Customised careers. In Handbook of Career Studies. Edited by P. Gunz Hugh and Maury Peiperl. London: Sage, pp. 188-210.

van den Brink, Marieke, and Yvonne Benschop. 2012. Slaying the seven-headed dragon: The quest for gender change in academia. Gender, Work and Organization 19: 71-92. [CrossRef]

Vinnicombe, Susan, and Val Singh. 2003. Women-only management training: An essential part of women's leadership development. Journal of Change Management 3: 294-306. [CrossRef]

White, Kate. 2003. Women and leadership in higher education in Australia. Tertiary Education and Management 9: 45-60. [CrossRef]

White, Kate, Sarah Riordan, Özlem Atay Ozkanli, and Jenny Neale. 2010. Cross culture perspective of gender and management in universities. South African Journal of Higher Education 24: 646-60.

(C) 2018 by the authors. Licensee MDPI, Basel, Switzerland. This article is an open access article distributed under the terms and conditions of the Creative Commons Attribution (CC BY) license (http:/ / creativecommons.org/licenses/by/4.0/). 